\title{
0415 VIOLENCE AGAINST CHILDREN IN SPAIN: A POPULATION-BASED EPIDEMIOLOGICAL APPROACH
}

E Gascon*, P Carrera, C Martos, M J Rabanaque Correspondence: Alicante University, University Apartado de correos, 99 03080-Alicante, Spain

10.1136/ip.2010.029215.415

Violence against children is recognised internationally as a serious public health, human rights, legal and social issue. There is evidence of societal factors involving the underlying conditions of society that influence violence, like economic inequalities. The aim of this study is to identify gender, age, nationality and socioeconomic intentional injury inequalities. Data from the 2006 Spanish Health Survey were analysed. Information related with intentional injuries was retrieved (injury frequency and place where injury happened, socioeconomic class and children nationality), reported by parents or main care giver. Cross-tabulations and $\chi^{2}$ tests were performed to investigate significant differences.

A total of 9122 children under 16 were surveyed. The observed intentional injury frequency was $2.8 \%$ of children population. Considering the place where aggression happened, $68.7 \%$ was at school, $16 \%$ in the street, $8 \%$ at sport and leisure area and only $2.7 \%$ at home. There was an age statistically difference in the violence events, with the highest frequency, $4 \%$, in age group 6-10 years. As social class decreases the frequency of having an aggression increases, social class I/II $2.13 \%$, social class V $3.97 \%$, but this social class gradient was not statistically significant.

Data from the Spanish National Health Survey provide an important population-based information about intentional injuries in children, considering the paucity of data on childhood violence. Although any statistically significant socioeconomic inequality has been found, that is similar with results found in previous studies, where there is no effect consistency at all when analyzing morbidity, specially less severity morbidity. 